\title{
İki Santimetreden Küçük İzole Böbrek Pelvis Taşlarında Semirijid ve Fleksibl Üreteroskopi Sonuçlarının Karşılaştırması
}

\section{Comparison of Semirigid and Flexible Ureteroscopy Results in Isolated Kidney Pelvis Stones Smaller than Two Centimeters \\ Osman BARUT $^{1}(\mathbb{D})$, Sefa RESIM ${ }^{1}$}

${ }^{1}$ Sütçü İmam Üniversitesi, Tıp Fakültesi, Üroloji Ana Bilim Dalı, Kahramanmaraş, TÜRKIYE

öz.

Amaç: Çalışmamızda böbrek pelvisinde izole $2 \mathrm{~cm}$ 'den küçük taşı olan hastaların tedavisinde semirijid ureteroskopi (S-URS) ve fleksibl üreteroskopi (F-URS) kulanımının etkinlik ve güvenilirliklerini karşılaştırmayı amaçladık.

Materyal ve Metod: iki $\mathrm{cm}$ 'den küçük izole böbrek pelvis taşı nedeniyle üreteroskopik taş tedavisi uygulanan toplam 45 hastanın verileri retrospektif olarak değerlendirildi. S-URS tüm hastalara rutin olarak uygulandı. S-URS ile taşlara böbrek pelvisinde erişilebiliyorsa doğrudan holmiyum lazer ile tedavi uygulandı. Taş erişilebilir değilse F-URS yapıldı. Gruplar taşsılık oranları, operasyon süreleri, hemoglobin düşüşü ve komplikasyonlar bakımından karşılaştıııldı.

Bulgular: $24(\% 53,3)$ hastaya S-URS ve $21(\% 46,7)$ hastaya F-URS yapıldı. íki grup arasında yaş, hidronefroz derecesi, ortalama taş boyutu ve taş tarafı bakımından anlamlı farklılı yoktu. Ortalama operasyon süresi S-URS grubunda $64,62 \pm 9,34$ dakika, F-URS grubunda $96,43 \pm 14,26$ dakika idi $(p=0,001)$. Gruplar arasında postoperatif komplikasyonlar açısından istatistiksel olarak anlamlı fark yoktu $(p=0,548)$. Postoperatif 1 . gün ve 1. ay takipte taşsızlık oranları S-URS grubunda sırasıyla $\% 79,2$ ve $\% 83,3$ ve F-URS grubunda $\% 80,9$ ve $\% 85,7$ idi $(p=0,768$ ve $p=0,574)$.

Sonuç: İki cm'den küçük böbrek taşlarında S-URS ve F-URS kullanımının oldukça başarılı ve güvenli yöntemler olduğunu gözlemledik. S-URS özellikle seçilmiş olgularda böbrek pelvisinde taşa sorunsuz bir şekilde ulaşılabiliyorsa uygulanabilecek güvenli bir tedavi yöntemidir.

Anahtar kelimeler: Böbrek taşı, Semirijid, Fleksibl, Üreteroskopi

Abstract

Background: In our study, we aimed to compare the efficiency and reliability of using semirigid ureteroscopy (S-URS) and flexible ureteroscopy (F-URS) in the treatment of patients with stones smaller than $2 \mathrm{~cm}$ in isolated renal pelvis.

Materials and Methods: The data of 45 patients who underwent ureteroscopic stone treatment for isolated renal pelvis stones smaller than $2 \mathrm{~cm}$ were evaluated retrospectively. S-URS was routinely applied to all patients. If the stones can be accessed in the renal pelvis with S-URS, direct treatment with holmium laser was applied. If the stone was not accessible, F-URS was made. Groups were compared in terms of stone-free rates, operation times, hemoglobin reduction, and complications.

Results: S-URS was performed in $24(53.3 \%)$ patients and F-URS in 21 (46.7\%) patients. There was no significant difference between the two groups in terms of age, degree of hydronephrosis, mean stone size and stone side. Mean operation time was $64.62 \pm 9.34$ minutes in the S-URS group and $96.43 \pm 14.26$ minutes in the F-URS group ( $p=0.001)$. There was no statistically significant difference between the groups in terms of postoperative complications $(p=0.548)$. In the postoperative 1 st day and 1st month follow-up, stone-free rates were $79.2 \%$ and $83.3 \%$ in the S-URS group, and $80.9 \%$ and $85.7 \%$ in the F-URS group, respectively $(p=0.768$ and $p=0.574)$.

Conclusions: We observed that the use of S-URS and F-URS were very successful and safe methods in kidney stones smaller than $2 \mathrm{~cm}$. S-URS is a safe treatment method that can be applied if the stone in the renal pelvis can be reached without any problem, especially in selected cases.

Key Words: Kidney stones, Semirigid, Flexible, Ureteroscopy
Corresponding Author/Sorumlu Yazar

Dr. Osman Barut

Sütçü İmam Üniversitesi, Tıp Fakültesi, Üroloji Ana Bilim Dalı,

Kahramanmaraş, TÜRKIYE

E-mail: osmanbrt@hotmail.com

Received / Geliş Tarihi: 11.01.2120

Accepted / Kabul Tarihi: 13.02.2021

DOI: $10.35440 /$ hutfd. 858497 


\section{Giriş}

İki cm'den küçük böbrek pelvis taşlarının tedavi seçenekleri arasında ekstrakorporeal şok dalga litotripsi (ESWL), fleksibl üreterorenoskopi (F-URS) ve perkütan nefrolitotomi (PNL) bulunmaktadır (1). Uzun tedavi süresi ve taşsızlık için ek prosedürlerlerin gereksinimi ESWL için en önemli dezavantajlardır. Taş kırma sistemleri ve endoürolojik tekniklerin tasarımlarındaki minyatürizasyon ve ilerlemeler ile birlikte bu boyuttaki taşların çoğu artık birçok merkezde F-URS ile yönetilebilmektedir (2). F-URS sırasında holmiyum: YAG lazer kullanımı, üst üriner sistem taşlarında tek seansta bile taş temizliğini sağlayabilmektedir (3). Semirid URS (S-URS) ise hala hem distal hem de proksimal üreter taşları için güvenli ve etkili bir şekilde kullanılmaktadır $(4,5)$. Sınırlı manevra kabiliyeti, orta ve alt kalikslere erişim zorluğu nedeniyle böbrek taşlarının ilk tedavi seçeneklerinden biri olmamasına rağmen S-URS, pelvise ulaşılabilen seçilmiş hasta grubunda taşların temizlenmesi amacıyla kullanılabilir. Bu hastalarda SURS'nin avantajı, daha büyük çalışma kanalına ve dolayısıyla daha büyük çalışma ekipmanına sahip olmasıdır. Buna ek olarak, daha yüksek irrigasyon akışı sayesinde daha iyi görüntüleme elde edilebilmektedir.

Bu çalışmada, 2 cm'den küçük böbrek pelvis taşlarının tedavisinde S-URS ve F-URS'nin etkinlik ve güvenirliklerini karşılaştırdık.

\section{Materyal ve Metod}

Çalışmamız için Kahramanmaraş Sütçü İmam Üniversitesi yerel etik kurulundan onay alındı (04/01/2021 tarih ve 2020/10/04 sayılı karar). Eylül 2016 ile Ekim 2020 tarihleri arasında $2 \mathrm{~cm}$ 'den küçük böbrek pelvis taşı tedavisi için SURS ( $n=24)$ ve F-URS $(n=21)$ uygulanan hastaların verileri retrospektif olarak değerlendirildi. 18 yaşından küçük, kaliks taşı, konjenital anomalisi, üreteropelvik bileşke obstrüksiyonu, üreteral darlığı veya aktif idrar yolu enfeksiyonu olan hastalar çalışma dışı bırakıldı. Üriner sistem ve taş özellikleri (taş boyutu, lokalizasyonu, önceki operasyon ve/veya ESWL öyküsü), operasyon süresi ve operasyon sonrası bulgular (taşsızlık oranı, hastanede kalış süresi) ile birlikte intraoperatif ve postoperatif komplikasyonlar kaydedildi. Taş boyutu, kontrastsız batın tomografi (BT) ile belirlenen en uzun çap olarak tanımlandı. Hidronefroz derecesi ultrason (USG) veya BT bulgularına göre; (a) kaliks ve renal pelvis dilatasyonu olmaması hidronefroz yok olarak, (b) sadece pelvik dilatasyon hafif hidronefroz olarak, (c) hafif kaliks genişlemesinin eşlik ettiği pelvik dilatasyon orta derecede hidronefroz olarak ve (d) böbrek parankim atrofisinin eşlik ettiği ileri derecede kaliks genişlemesi şiddetli hidronefroz olarak sınıflandırıldı.

Tüm hastaların ameliyat öncesi idrar tahlili, serum kreatinin ve tam kan sayımını içeren labaoratuvar parametreleri kaydedildi. Her iki gruba operasyon öncesi benzer profilaktik antibiyotik tedavisi (sefazolin $1 \mathrm{~g}$ intravenöz) uygulandı. Gruplar taşsızlık oranları, operasyon süreleri, he- moglobin düşüşü, intraoperatif ve postoperatif komplikasyonlar (Clavien-Dindo sınıflamasına göre), postoperatif analjezik gereksinimi ve hastanede kalış süreleri bakımından karşılaştırıldı.

\section{Operasyon Tekniği}

Hastaların tümü genel anestezi altında dorsal litotomi pozisyonunda opere edildi. Üreteri aktif olarak genişletmek ve hidrofilik kılavuz tel yerleştirmek için tüm hastalara $6 \mathrm{~F}$ çalışma kanallı semirijid üretroskop (Wolf, Knittlingen, Germany) ile S-URS yapıldı. İhtiyaç halinde üreteral balon dilatasyon kullanıldı. S-URS ile böbrek pelvisinde ulaşılan taşlar holmiyum lazer (Quanta System, Spa Litho, Solbiate Olona, Italy) ile 0.6 ila $0.8 \mathrm{~J}$ enerji ayarı ve 8 ila $10 \mathrm{~Hz}$ hızda 272 veya $365 \mu \mathrm{m}$ fiber kullanılarak parçalandı. Taşlara ulaşılamadığında, ikinci bir 0.035 / 0.038 inç güvenlik kılavuz teli semirijid üreteroskop vasıtasıyla renal pelvise yerleştirildi. Üreteroskop çıkarıldıktan sonra, optimal görüntü sağlayabilmek, intrarenal basıncı düşürmek ve taş parçalarının çıkarılmasını kolaylaştırmak için 10/12 F çaplı üreteral erişim kılıfı yerleştirildi ve 3.6 F çalışma kanallı F-URS (Olympus, Hamburg, Germany) kullanıldı. Taşlar, benzer lazer enerji ayarları ve $200 \mu \mathrm{m}$ fiberle parçalandı. Litotripsi sonrası tüm olgulara rutin olarak $4.8 \mathrm{~F}$ double-J stent yerleştirildi ve operasyondan 3 veya 4 hafta sonra çıkarıldı.

Taşsızlık intraoperatif floroskopi ile, postoperatif 1. gün düz radyografi ile ve postoperatif 1 . ayda düz radyografi ve ultrasonografi ile değerlendirildi. BT, ultrason veya düz radyografide rezidüel taş tespit edildiğinde yapıldı. Klinik olarak önemsiz rezidüel fragmanlar 4 mm'den küçük asemptomatik, obstrüksiyon yapmayan taşlar olarak tanımlandı.

\section{istatistiksel analiz}

Veri toplama işlemleri IBM SPSS 20.0 (IBM Inc., Chicago, IL, ABD) kullanılarak gerçekleştirildi. Değişkenlerin normal dağılıma uygunluğu Shapiro-Wilk testi ile belirlendi ve normal dağılım gösteren değişkenler ortalama \pm standart sapma olarak sunuldu. Gruplar arasındaki farklar bağımsız örneklem t testi ile analiz edildi. Kategorik değişkenler frekans ve yüzde olarak sunuldu ve ki-kare testi ile karşılaştırıldı. $<0,05$ 'lik bir $p$ değeri istatistiksel olarak anlamlı kabul edildi.

\section{Bulgular}

İki cm'den küçük izole böbrek pelvis taşı olan 45 hastanın 24 'inde $(\% 53,3)$ semirijid üreteroskopla taşa ulaşılırken diğer $21(\% 46,7)$ hastada ulaşılamadı ve F-URS yapıldı. Yaş, cinsiyet, taş boyutu ve taş tarafı her iki grupta benzerdi (sırasıyla $p<0,697, p<0,834, p<0,478$ ve $p<0,926$ ) (Tablo 1).

Ortalama operasyon süresi S-URS grubunda $64.62 \pm 9.34$ dakika (dk), F-URS grubunda $96.43 \pm 14.26 \mathrm{dk}$ idi ve istatistiksel olarak anlamlıydı ( $p=0.001)$. Postoperatif 1 . gün ve 1. ay takipte taşsızlık oranları S-URS grubunda sırasıyla $\% 79,2$ ve $\% 83,3$ ve F-URS grubunda $\% 80,9$ ve $\% 85,7$ $(p=0,768$ ve $p=0,574)$ idi, 
Gruplar hemoglobin düşüşü bakımından karşılaştırıldığında anlamlı farklılık saptanmadı (sırasıyla 0,62 $\pm 0,31$ $\mathrm{g} / \mathrm{dL}$ ve $0,66 \pm 0,22 \mathrm{~g} / \mathrm{dL}, \mathrm{p}=0,249)$. Hiçbir hastaya kan transfüzyonu ihtiyacı olmadı. S-URS grubunda üç hastada ve F-URS grubunda iki hastada postoperatif ateş görüldü $(p=0,548)$. Tüm bu hastalar ateş düşürücü ilaçlarla (Clavien 1) tedavi edildi. S-URS grubunda iki hastada ve F-URS grubunda bir hastada postoperatif narkotik analjezik gereksinimi görüldü $(p=0,654)$. Hastanede kalış süresi S-URS grubunda $25,34 \pm 6,18$ saat ve F-URS grubunda 24,82 \pm 6,24 saat idi ve istatistiksel olarak anlamlı farklılık görülmedi $(p=0,457)$. Hastaların hiçbirinde ürosepsis ve major komplikasyon (Clavien 4-5) görülmedi. Intraoperatif ve postoperatif parametreler Tablo 2'de verilmiştir.

Tablo 1. Gruplara ait demografik veriler ve taş özellikleri.

\begin{tabular}{|l|c|c|c|}
\hline Parametreler & Semirijid URS & Fleksibl URS & P-değeri \\
\hline Hasta sayısı (n, \%) & $24(\% 53,3)$ & $21(\% 46,7)$ & \\
\hline Yaş (yıl) & $46,62 \pm 7,35$ & $45,84 \pm 8,34$ & 0,697 \\
\hline Cinsiyet (n, \%) & & & 0,834 \\
\hline Erkek & $15(\% 62,5)$ & $13(\% 61,9)$ & \\
\hline Kadın & $9(\% 37,5)$ & $8(\% 38,1)$ & \\
\hline Taş boyutu (mm) & $14,16 \pm 2,45$ & $14,42 \pm 2,37$ & 0,478 \\
\hline Taş tarafı (n, \%) & & & 0,926 \\
\hline Sağ & $13(\% 54,2)$ & $11(\% 52,4)$ & \\
\hline Sol & $11(\% 45,8)$ & $10(\% 47,6)$ & \\
\hline Hidronefroz (n, \%) & & & 0,642 \\
\hline Yok / hafif & $14(\% 58,3)$ & $12(\% 57,1)$ & \\
\hline Orta / şiddetli & $10(\% 41,6)$ & $9(\% 42,9)$ & \\
\hline
\end{tabular}

Tablo 2. Gruplara ait intraoperatif ve postoperatif verilerin karşılaştırilması.

\begin{tabular}{|l|c|c|c|}
\hline Parametreler & Semirijid URS & Fleksibl URS & P-değeri \\
\hline $\begin{array}{l}\text { Operasyon süresi } \\
\text { (dakika) }\end{array}$ & $64,62 \pm 9,34$ & $96,43 \pm 14,26$ & 0,001 \\
\hline Taşsızlık (n, \%) & & & \\
\hline Postoperatif 1. gün & $19(\% 79,2)$ & $17(\% 80,9)$ & 0,768 \\
\hline Postoperatif 1. ay & $20(\% 83,3)$ & $18(\% 85,7)$ & 0,574 \\
\hline Ateş & $3(\% 12,5)$ & $2(\% 9,5)$ & 0,548 \\
\hline $\begin{array}{l}\text { Hemoglobin düşüşü } \\
\text { (g/d) }\end{array}$ & $0,62 \pm 0,31$ & $0,66 \pm 0,22$ & 0,249 \\
\hline $\begin{array}{l}\text { Postoperatif narko- } \\
\text { tik analjezik ihtiyacı } \\
\text { (n, \%) }\end{array}$ & $2(\% 8,3)$ & $2(\% 9,5)$ & 0,654 \\
\hline $\begin{array}{l}\text { Hastanede kalış sü- } \\
\text { resi (saat) }\end{array}$ & $28,34 \pm 6,18$ & $28,82 \pm 6,24$ & 0,457 \\
\hline
\end{tabular}

URS: Üreterorenoskopi

\section{Tartışma}

Böbrek taşlarının tedavisinde taş boyutunun ve lokalizasyonunun etkisi konusunda bir çok çalışma yapılmıştır. Güncel kılavuzlara göre, 1-2 cm arası alt pol harici böbrek taşlarının tedavisinde ESWL, F-URS veya perkütan nefrolitotomi (PNL) hastanın ve cerrahın tercihine göre ilk seçenek olarak uygulanabilir (6). Endoskopik cihazların minyatürizasyonu, optik sistemlerin kalitesinin artması, holmiyum lazerin kullanıma girmesi ve endoürolojik cerrahi deneyimin artması ile birlikte semirijid ve fleksibl üreteroskopi işleminin endikasyonları da oldukça genişlemiştir. Tüm üreter seyri boyunca, hatta böbrek içerisindeki taşlar bu yöntemlerle tedavi edilebilir hale gelmiştir (1). Cepeda ve ark. (7) böbrek taşı nedeniyle opere ettikleri 150 hastalık serilerinde F-URS sonrası \%85.7 taşsızlık oranı elde etmiş ve operasyondan 3 ay sonra bu oran \%91'e ulaşmıştır. Böbrek alt pol taşlarında yapılan çalışmalarda F-URS sonrası taşsızlık oranı \%65-\%91 gibi geniş bir aralıkta değişmektedir (8). Son zamanlarda $2 \mathrm{~cm}$ 'den büyük taşların tedavisinde F-URS yapılmış 106 hastalık bir başka seride \%70 oranında başarı sağlanmıştır (9). Reşorlu ve ark. (10) ESWL, PNL veya F-URS yaptıkları 437 hastanın sonuçlarını karşılaştırmış ve taşsızlık oranlarını sırasıyla \%66.5, \%91.4 ve \%87 olarak saptamışlardır. Bozkurt ve ark. (8) böbrek taşı nedeniyle PNL veya F-URS yaptıkları iki grubu karşılaştırmış ve taşsızlık oranlarını sırasıyla \%92.8 ve \%89.2 şeklinde benzer bulmuşlardır.

Literatüre bakıldığında çalışmalar, F-URS'i böbrek taşlarından ziyade üst üreter taşlarında daha başarılı olduğunu göstermektedir. Hyams ve ark. (11) 2 cm'den küçük proksimal üreter taşlarının tedavisinde F-URS ile \%95 oranında taşsızlık oranı rapor etmişlerdir. Bu çalışmaya benzer şekilde Karadağ ve ark. (12) proksimal üreter taşlarında, rijid URS ile F-URS'i karşılaştırmış ve rigid üreteroskopi yapılanlarda \%76, F-URS uygulananlarda ise \%93 oranında taşsızlık oranı saptamışlardır.

F-URS, böbrek taşı tedavisi için güvenli ve etkili bir yöntem olmasına rağmen bazı önemli dezavantajları da bulunmaktadır. Çalışma kanallarının küçük boyutlu olması yalnızca ince taş forsepsi ve lazer fiberlerin kullanımına izin vermekte ve bu da operasyon süresinin uzamasına neden olmaktadır. Bununla birlikte düşük irigasyon sıvı basıncında çalışıması görüntü kalitesini düşürebilmektedir (13). Bu nedenle irigasyon iyi görüntüyü sağlayacak kadar hızlı, taşı hareket ettirmeyecek ve böbrek içi basıncı arttırmayacak kadar yavaş olmalıdır. Bu denge ancak deneyimli asistanın elindeki elle sıkılan puar ile sağlanabilmektedir. F-URS'nin en büyük dezavantajlarından biri de endoskopik taş cerrahisi sırasında taş fragmanlarının nitinol basket ile ekstraksiyonu ve buna bağlı olarak operasyon süresinde uzama ile ilgili yaşanan sıkıntıdır. Bu nedenle son dönemlerde taş fragmanlarının temizlenmesi için çalışma kanaIından gönderilen magnet aparatlarla ilgili çalışmalar bulunmaktadır $(14,15)$.

Küçük çaplı, kamera çözünürlükleri, ışık difüzyonları ve görüş alanları arttırılmış fleksibl üretroskoplar doğal olarak rijid üretroskoplara göre oldukça kırılgan ve hasara yatkındırlar. Özellikle lazerin yanlış konumda ateşlenmesi, yardımcı enstruman içerideyken uç kısmın aşırı defleksiyonu ve aşırı bükülme fleksibl üretroskoplarda onarım gerektiren ciddi hasarlara neden olabilmektedir (16). F-URS'de sık görülen sorunlardan biri aletin kullanıldıkça defleksiyon mekanizmalarında oluşan yorgunluktur. Bu durum dijital ve fiberoptik aletlerde benzer oranda görülmektedir. Mustescu ve ark. (17) yaptıkları bir çalışmada 22 kullanım sonunda fiberoptik F-URS'de $\% 10$, dijital F-URS'de ise $\% 0$ oranında defleksiyon kaybı saptamışlardır. Binbay ve ark. 
(18) tarafından ise tamire kadar fiberoptik f-URS ile ortalama 17, dijital f-URS ile ise ortalama 21 kullanım bildirilmiştir.

Semirid üretroskopların tasarımında gelişmeler sebebiyle kullanım kolaylığı ve çalışma elemanlarının kolay kontrol edilebilir olması sadece distal üreter taşları için değil aynı zamanda proksimal üreter ve böbrek pelvis taşları için de kullanımına olanak sağlamaktadır (19). S-URS'nin en büyük dezavantajı, aletin taş parçalanması sırasında sınırlı bir manevra kapasitesine sahip olması ve diğer kalikslere, özellikle alt kalikse düşen fragmanlara bu aletle ulaşılamamasıdır (20).

Süer ve ark.'nın (21) böbrek pelvisinde 1-2 cm arası taşı olan 88 hastalık serilerinde, hastaların \% 55'inde F-URS'ye ihtiyaç duyulmadan rijid URS ile tedavi edildiği bildirilmiştir. Yine aynı çalışmada taşsızlık oranı rijid URS grubunda \%83, F-URS grubunda \%87 olarak raporlanmıştır. Yine bir başka çalışmada, Atış ve ark. (22) böbrek pelvis taşı olan 47 hastanın 25'inde taşları S-URS ile fragmente ederken geri kalan 22 hastada F-URS uygulamışlar. Ortalama operasyon süresinin S-URS grubunda anlamlı olarak daha kısa olduğunu raporlamışlardır. Postoperatif 1 . günde başarı oranını S-URS grubunda \%72 ve F-URS grubunda \%81.8 bularak anlamlı fark olmadığını bildirmişlerdir.

Biz kliniğimizde rutin olarak F-URS'den önce S-URS uygulamaktayız. Çalışmamızda, 2 cm'den küçük izole böbrek pelvis taşı tanısıyla opere edilen 48 hastanın 25 'nde, sorunsuz bir şekilde böbrek pelvisine S-URS ile ulaşıldığı için taşlar holmiyum lazer ile fragmente edildi. Diğer 23 hastada küçük üreter çapı, semirijid üreteroskopun kısa gelmesi veya üreterin king yapması gibi nedenlerden dolayı pelvisteki taşa ulaşılamadı ve F-URS yapıldı. Çalışmamızda ortalama operasyon süresi F-URS grubunda anlamlı olarak daha yüksekti. Postoperatif 1. gün ve 1. ay taşsızlık oranları karşılaştırıldığında ise literatürle uyumlu olarak S-URS ve F-URS yapılan gruplar arasında anlamlı farklılık gözlenmedi. Ek olarak yaş, cinsiyet, hidronefroz derecesi, komplikasyon oranı ve hastanede kalış süresi her iki grupta benzerdi.

Çalışmamızın temel amacı böbrek pelvis taşlarında S-URS'i ilk tedavi seçeneklerinden biri olarak önermek değildir. Amacımız, semirijid üretroskopla sorunsuz biçimde böbrek pelvisinde taşa ulaşılabilen seçilmiş olgularda SURS'nin de kullanılabileceğini ve böylece hasara yatkın ve pahalı olan fleksibl aletlerin uzun süreli kullanılabileceğini belirlemekti. Ayrıca her iki üreteroskopi cerrahi tekniği incelendiğinde operasyon süresinin S-URS yapılanlarda daha kısa sürmesinin önemli bir avantaj olduğunu düşünmekteyiz. Bununla birlikte, üst üriner sistem erişimi zor hastalarda S-URS yapılmasını önermiyoruz.

Çalışmamızın başlıca limitasyonları retrospektif dizaynı ve tek merkezli olmasıydı. Maliyet analizi açısından karşılaştırma yapılmaması diğer bir limitasyondu. Daha doğru sonuçlar elde etmek için çok sayıda hasta ile çok merkezli çalışmalara ihtiyaç duyulmaktadır.

\section{Sonuç}

İki cm'den küçük böbrek pelvis taşlarında F-URS ilk tedavi seçenekleri arasında yer almasına rağmen, semirijid üretroskopla böbrek pelvisine ulaşılabilen seçilmiş olgularda S-URS etkili ve güvenli bir şekilde uygulanabilir. F-URS ile kıyaslandığında daha kısa ameliyat sürelerine, benzer başarı ve komplikasyon oranlarına sahiptir. Ayrıca, bu tür olgularda S-URS kullanımı oldukça pahalı ve hassas yapıda olan fleksibl üretroskopların uzun dönem kullanılımına olanak sağlayacaktır.

Etik onam: Çalışma için Kahramanmaraş Sütçü Imam Üniversitesi Tıp Fakültesi Klinik araştırmalar etik kurulundan etik onay alındı (04/01/2021 tarih ve 2020/10/04 sayılı karar).

\section{Yazar Katkıları:}

Konsept: O.B.

Literatür Tarama: O.B., S.R.

Tasarımı: O.B., S.R.

Teknik ve malzeme desteği: O.B., S.R.

Veri toplama: O.B.

Veri analizi ve yorumlama: O.B., S.R.

Makale yazımı: O.B., S.R.

içeriğin eleştirel incelenmesi: S.R.

Çıkar Çatışması: Yazarlar çıkar çatışması bildirmemişlerdir. Finansal Destek: Yazarlar, bu çalışmada herhangi bir finansal destek almadıklarını beyan etmişlerdir.

\section{Kaynaklar}

1. Türk C, Petř́ik A, Sarica K, Seitz C, Skolarikos A, Straub M, et al. EAU Guidelines on Diagnosis and Conservative Management of Urolithiasis. Eur Urol. 2016;69(3):468-74.

2. Afane JS, Olweny EO, Bercowsky E, Sundaram CP, Dunn $M D$, Shalhav AL, et al. Flexible ureteroscopes: a single center evaluation of the durability and function of the new endoscopes smaller than 9Fr. J Urol. 2000;164(4):1164-8.

3. Liu DY, He HC, Wang J, Tang $Q$, Zhou YF, Wang MW, et al. Ureteroscopic lithotripsy using holmium laser for 187 patients with proximal ureteral stones. Chin Med J. 2012;125(9):1542-6.

4. Slam J, Tricia D. Greene and Mantu Gupta: Treatment of proximal ureteral calculi: Holmium: YAG laser ureterolithotripsy versus extracorporeal shock wave lithotripsy. J Urol. 2002;167:1972-6.

5. Kumar A, Nanda B, Kumar N, Kumar R, Vasudeva P, Mohanty NK. A prospective randomized comparison between shockwave lithotripsy and semirigid ureteroscopy for upper ureteral stones $<2 \mathrm{~cm}$ : A single center experience. J Endourol. 2015;29:47-51.

6. Hughes $T$, Ho HC, Pietropaolo A, Somani BK. Guideline of guidelines for kidney and bladder stones. Turk J Urol. 2020;46(1) 104-112.

7. Cepeda M, Amón JH, Mainez JA, Rodríguez V, Alonso D, Martínez-Sagarra JM. Flexible ureteroscopy for renal stones. Actas Urol Esp. 2014;38(9):571-5.

8. Bozkurt OF, Resorlu B, Yildiz Y, Can CE, Unsal A. Retrograde intrarenal surgery versus percutaneous nephrolithotomy in the management of lower-pole renal stones with a diameter of 15 to $20 \mathrm{~mm}$. J Endourol. 2011;25(7):1131-5.

9. Palmero JL, Castelló A, Miralles J, Nuño de La Rosa I, Garau C, Pastor JC. Results of retrograde intrarenal surgery in the 
treatment of renal stones greater than $2 \mathrm{~cm}$. Actas Urol Esp. 2014;38(4):257-62.

10. Resorlu B, Unsal A, Ziypak T, Diri A, Atis G, Guven S, et al. Comparison of retrograde intrarenal surgery, shockwave lithotripsy, and percutaneous nephrolithotomy for treatment of medium-sized radiolucent renal stones. World J Urol. 2013;31(6):1581-6.

11. Hyams ES, Monga M, Pearle MS, Antonelli JA, Semins MJ, Assimos DG, et al. A prospective, multi-institutional study of flexible ureteroscopy for proximal ureteral stones smaller than $2 \mathrm{~cm}$. J Urol. 2015;193(1):165-9.

12. Karadag MA, Demir A, Cecen K, Bagcioglu M, Kocaaslan R, Altunrende F. Flexible ureterorenoscopy versus semirigid ureteroscopy for the treatment of proximal ureteral stones: a retrospective comparative analysis of 124 patients. Urol J. 2014;11(5):1867-72.

13. Miernik A, Schoenthaler $M$, Wilhelm $K$, Wetterauer $U$, Zyczkowski $M$, Paradysz $A$, et al. Combined semirigid and flexible ureterorenoscopy via a large ureteral access sheath for kidney stones $>2 \mathrm{~cm}$ : a bicentric prospective assessment. World J Urol. 2014;32:697-702.

14. Mir SA, Best SL, McLeroy S, Donnally CJ 3rd, Gnade B, Hsieh $\mathrm{JT}$, et al. Novel stone-magnetizing microparticles: in vitro toxicity and biologic functionality analysis. J Endourol. 201;25(7):1203-7.

15. Tan YK, Best SL, Donnelly C, Olweny E, Kapur P, Mir SA, et al. Novel iron oxide microparticles used to render stone fragments paramagnetic: assessment of toxicity in a murine model. J Urol. 2012;188(5):1972-7.

16. User HM, Hua V, Blunt LW, Wambi C, Gonzalez CM, Nadler RB. Performance and durability of leading flexible ureteroscopes. J Endourol. 2004;18(8):735-8.

17. Multescu R, Geavlete B, Georgescu D, Geavlete P. Conventional fiberoptic flexible ureteroscope versus fourth generation digital flexible ureteroscope: a critical comparison. J Endorol. 2010;24:17-21.

18. Binbay M, Yuruk E, Akman T, Ozgor F, Seyrek M, Ozkuvanci $U$, et al. Is there a difference in outcomes between digital and fiberoptic flexible ureterorenoscopy procedures? J Endourol. 2010;24(12):1929-34.

19. Basillote JB, Lee DI, Eichel L, Clayman RV. Ureteroscopes: flexible, rigid, and semirigid. Urol Clin North Am. 2004;31:21-32.

20. Bryniarski P, Paradysz A, Zyczkowski M, Kupilas A, Nowakowski K, Bogacki R. A randomized controlled study to analyze the safety and efficacy of percutaneous nephrolithotripsy and retrograde intrarenal surgery in the management of renal stones more than $2 \mathrm{~cm}$ in diameter. J Endourol. 2012;26(1):52-7.

21. Süer E, Gülpinar Ö, Özcan C, Göğüş Ç, Kerimov S, Şafak M. Predictive factors for flexible ureterorenoscopy requirement after rigid ureterorenoscopy in cases with renal pelvic stones sized 1 to $2 \mathrm{~cm}$. Korean J Urol. 2015;56(2):13842.

22. Atis G, Gurbuz C, Arikan O, Canat L, Kilic M, Caskurlu T. Ureteroscopic management with laser lithotripsy of renal pelvic stones. J Endourol. 2012;26:983-7. 